\title{
Enhancement of Oxygen and Moisture Permeability with Illite-Containing Polyethylene Film
}

\author{
Dong Min Seong, Hyesun Lee, and Jeong Ho Chang (D) \\ Center for Convergence Bioceramic Materials, Korea Institute of Ceramic Engineering and Technology, Cheongju 28160, Korea
}

(Received October 6, 2019; Revised October 29, 2019; Accepted October 31, 2019)

\begin{abstract}
This work reports the preparation of ceramic hybrid films with illite-polyethylene composites analyzed as a function of concentration of added illite in polyethylene. The enhancement of oxygen and water-vapor transmission rate of illite-polyethylene film was evaluated to determine its influence on the freshness in fruit packaging. Particle size of illite materials was controlled in the range of $1 \sim 10 \mu \mathrm{m}$ and then mixed with LDPE to form the masterbatch. Ceramic hybrid films were prepared through a blown film making process. To determine the dispersity and abundancy of illite materials in the polyethylene matrix, various characterizations of illite-PE hybrid masterbatch and films were performed using SEM, TGA, and FT-IR. The oxygen and water-vapor transmission rate of illite-polyethylene film was found to be two times higher than that of LDPE film.
\end{abstract}

Key words : Illite, Polyethylene, Films, Oxygen transmission rate, Functional application

\section{Introduction}

$\mathrm{T}$ o improve the storage functionality of polyethylene film as a packaging material, efforts have been made to develop various packaging technologies, including modified atmosphere packaging (MAP), and controlled atmosphere packaging (CAP). ${ }^{1-3)}$ The packaging of fruit and vegetables in particular is problematic. Over time after packaging, it can lead to the generation of off-flavors, and the emitting of ethylene gas resulting from respiration. ${ }^{4)}$ Conventional technologies to address this problem have included increasing oxygen permeability through micropores formed by laser material processing technologies, and the removal of ethylene gas by means of $\mathrm{CaO}$ or activated carbon. ${ }^{5,6)}$ However, micropores reduce the tensile strength of the packaging film, increasing potential tearing of the film, which can allow contamination sources, such as microorganisms and impurities, to infiltrate into the packaging material. The use of $\mathrm{CaO}$ or activated carbon makes waste treatment difficult. $^{7)}$

To overcome these problems with a method that does not involve micropores or activated carbon, this article proposes adding ceramic powder into the raw materials of the packaging film, to impregnate the polymer matrix with ceramic powder to increase oxygen permeability. The ceramic material that was chosen in this study was illite, which is rare worldwide, but about 500,000,000 tons are found in reserves

${ }^{\dagger}$ Corresponding author: Jeong Ho Chang

E-mail : jhchang@kicet.re.kr

Tel : +82-43-913-1510 Fax : ++82-43-913-1599

ORCID

https://orcid.org/0000-0002-0548-0758 in Yeongdong-gun, Chungbuk, South Korea. ${ }^{8)}$ Illite is a platy clay mineral and has a layered alumino silicate structure consisting of two silica tetrahedrons and one alumina octahedron. The chemical formula of illite is $\left(\mathrm{KH}_{3} \mathrm{O}\right)$ $(\mathrm{AlMgFe})_{2}(\mathrm{SiAl})_{4} \mathrm{O}_{10}\left[(\mathrm{OH})_{2}\left(\mathrm{H}_{2} \mathrm{O}\right)\right]$. The illite material used in this study was provided by Medexhealing Co., Ltd. and Yongkoong Illite Co., Ltd.

When illite powder is mixed without pretreatment with polyethylene to prepare a film, the ceramic powder forms a mass, which decreases the film strength and prevents the uniform dispersion of the powder in the film. To avoid forming agglomerates, the particle size of the illite powder should be limited to $10 \mu \mathrm{m}$ or smaller. ${ }^{9-11)}$ Even when the particle size is controlled, adding illite to the film preparation in the form of powder hinders its dispersion in the film. Therefore, a master batch in the form of pellets was prepared by highly concentrating illite and then dispersing it in the basic polyethylene resin.

Figure 1 shows the flow chart for the manufacturing of the master batch and the film. In this study, an illite-containing film was manufactured using the illite master batch, and the dispersion of the illite contained in the film was analyzed by scanning electronic microscopy (SEM). In addition, the effect of adding the ceramic to the film was evaluated in terms of oxygen permeability, and moisture permeability, which can affect the freshness and storage quality of packaged fruit or packaged agricultural, livestock and fishery products.

\section{Experimental Procedures}

\subsection{Chemical reagents}

The melting index and density of the low-density polyeth- 


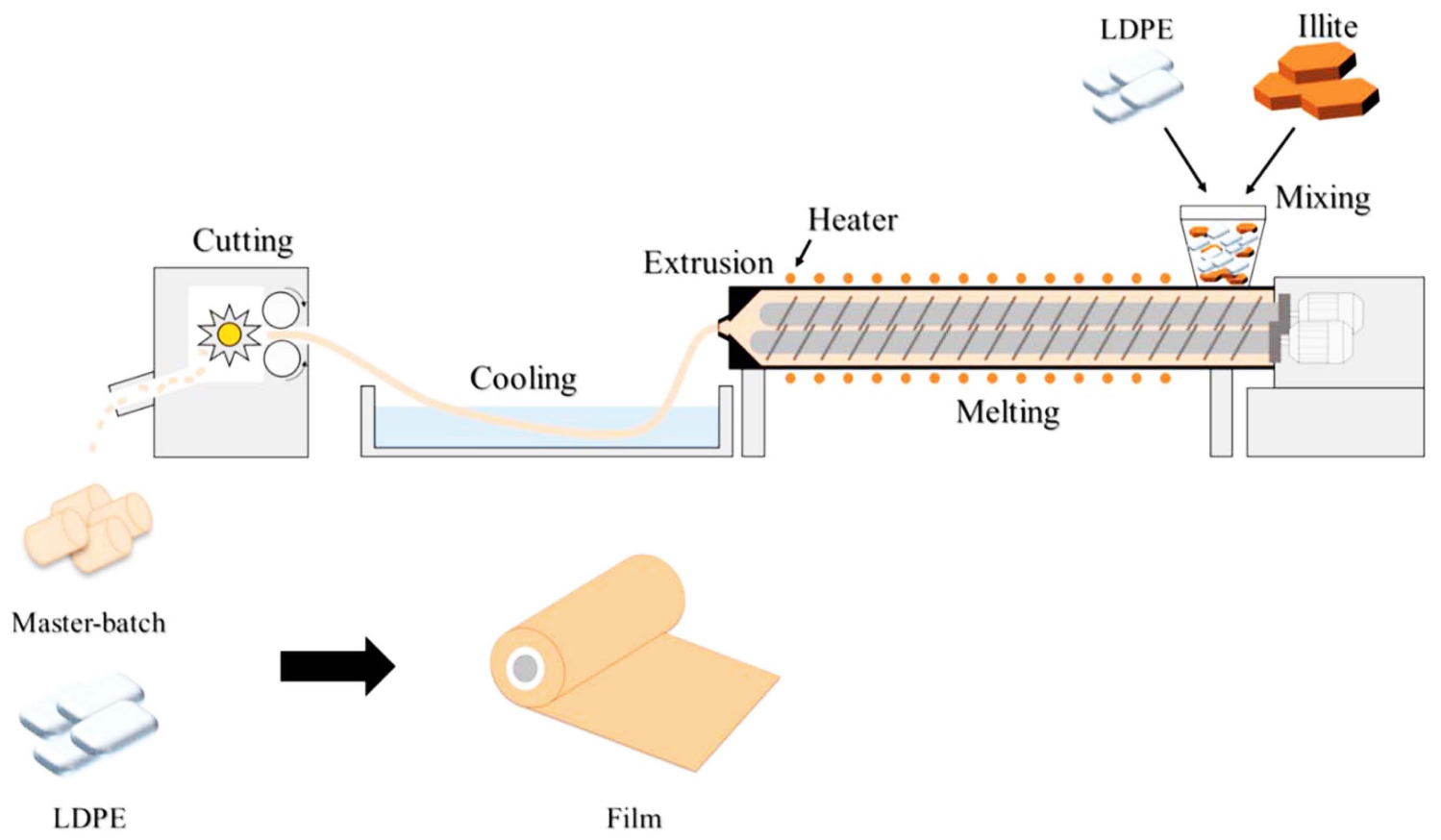

Fig. 1. Scheme of preparation process of illite-containing polyethylene films.

ylene (LDPE) used in the preparation of the master batch were $24.0 \mathrm{~g} / 10 \mathrm{~min}\left(190^{\circ} \mathrm{C}, 2.16 \mathrm{~kg}\right)$ and $0.915 \mathrm{~g} / \mathrm{cm}^{3}$, respectively. The illite was provided in two forms by Medexx Inc. and Yongkoong Illite Inc. Each illite product was pulverized to a particle size in the range of $1 \sim 10 \mu \mathrm{m}$ before preparing the master batch. The size and specific surface area of the pulverized illite particles were analyzed using a particle size analyzer, and by performing Brunauer-Emmett-Teller surface area analysis.

\subsection{Preparation of the LDPE and Illite master-batch}

To control the illite content (30 wt.\%) in the master batch in the experiment, the feed rates of the pure LDPE and illite from two feeders were measured. To prepare the polyethylene-illite hybrid master batch, illite and polyethylene were fed at a rate of 30\%:70\% using a biaxial co-rotation type extruder at screwing rates of $280 \mathrm{rpm}$ and $480 \mathrm{rpm}$, at 80 to $190^{\circ} \mathrm{C}$. The extruded material from the screws was pelletized using a pelletizer (rate: $4.3 \mathrm{~Hz}$ ) to produce the final master batch products. ${ }^{12,13)}$

\subsection{Preparation of LDPE and Illite Film}

Illite-containing films were prepared by mixing the illite master batch with polyethylene at selected ratios using a blow film extrusion apparatus. The illite content measured in the prepared illite-containing film was $1.6 \%$ to $1.8 \%$. The film thickness, measured using Vernier calipers, was 0.04 to $0.05 \mathrm{~mm}$. The morphology of the film samples was analyzed by SEM.

\subsection{Instrumentation}

The pulverization was performed with SJ-500 equipment
(Nisshin) at a feed rate of $0.43 \mathrm{~kg} / \mathrm{hr}$ under the air pressure of $0.74 \mathrm{MPa}$. The particles were analyzed with the wet mode of the LA-960 equipment (HORIBA). The specific surface area of the particles was measured by TriStar II 3020 equipment (Micromeritics). Nitrogen was used as the adsorption gas. The thermogravimetric analysis (TGA) was performed with Q600 TA equipment in nitrogen atmosphere at a rate of $10^{\circ} \mathrm{C} / \mathrm{min}$ from $25^{\circ} \mathrm{C}$ to $700^{\circ} \mathrm{C}{ }^{14)} \mathrm{MIRA} 3 \mathrm{SEM}$ equipment (TESCAN) was used to scan the surface of the samples to analyze the dispersion of illite in the polymer matrix of the master batch and the films.

The master batch samples were cut in parallel in the direction of extrusion, and the surface was coated with platinum to obtain images of the cross-sections at $5 \mathrm{kV}$. The film samples were cut into $5 \mathrm{~mm}$ by $5 \mathrm{~mm}$ sizes, and the surface was also coated with platinum to obtain images of the crosssections at $10 \mathrm{kV}$.

The oxygen permeability of the film was analyzed by measuring a total of six times. The amount of oxygen permeating a specimen having an area of $1.131 \mathrm{~cm}^{2}$ in $30 \mathrm{~min}$ at $23^{\circ} \mathrm{C}$ and $50 \% \mathrm{RH}$ was determined using $\mathrm{C} 230$ equipment (Labthink) according to the masking method specified in ASTM D3985. The moisture permeability of the film was analyzed by measuring a total of five times. The amount of moisture permeating a specimen having an area of 33.18 $\mathrm{cm}^{2}$ for a test interval of $60 \mathrm{~min}$ at $38^{\circ} \mathrm{C}$ and $90 \% \mathrm{RH}$ was obtained with W3/031equipment (Labthink) following the method specified in ASTM E96.

\section{Results and Discussion}

Figure 2 shows the size and specific surface area of the 


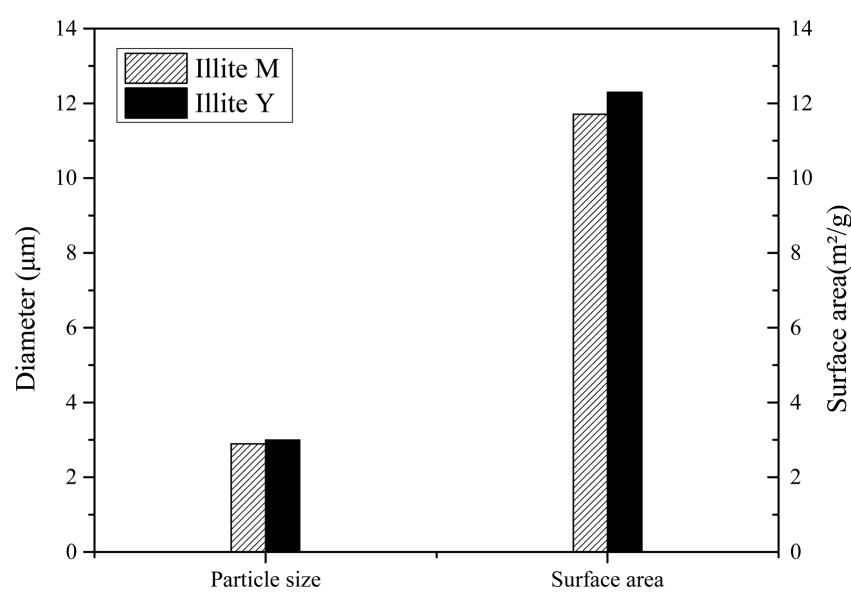

Fig. 2. Comparison of particle size and surface areas of illite samples.

particles prepared by pulverizing illite with a jet mill. Illite $\mathrm{M}$ represents the illite provided by Medexhealing Co., Ltd., and Illite Y was received from Yongkoong Illite Co., Ltd. The specific surface area of Illite $\mathrm{M}$ and Illite $\mathrm{Y}$, measured by BET analysis, was $11.7 \mathrm{~m}^{2} / \mathrm{g}$ and $12.29 \mathrm{~m}^{2} / \mathrm{g}$, respectively.
The particle size analysis (PSA) showed that the mean particle size of Illite $\mathrm{M}$ and Illite $\mathrm{Y}$ was $2.89 \mu \mathrm{m}$ and $2.99 \mu \mathrm{m}$, respectively, indicating the size of most particles was well controlled below $10 \mu \mathrm{m}$.

Figure 3 shows the SEM images of the composite polyethylene master batch and the films. They show illite particles of less than $10 \mu \mathrm{m}$ were well dispersed in the polyethylene matrix of the master batch. The SEM images of the film also show that the illite particles were uniformly dispersed without agglomeration in the polyethylene matrix. This is consistent with previous studies on adding fillers to polymers effectively using masterbatches. ${ }^{15-17)}$

Figure 4 shows the TGA results for the illite content in the master batch and the films. The rapid decrease in weight around $400^{\circ} \mathrm{C}$ was caused by the combustion of polyethylene. The final illite content was estimated in the stable interval after $500^{\circ} \mathrm{C} .^{18)}$ The TGA result in the master batch showed that the illite content reached about $30 \%$, indicating that the content was well controlled. The TGA also showed that illite content in the films was $1.6 \%$ to $1.8 \%$.

Figure 5 shows the variation in film properties depending on the illite content in terms of oxygen permeability and moisture permeability. ${ }^{19)}$ Fig. 5 (a) shows the oxygen perme-

(a)

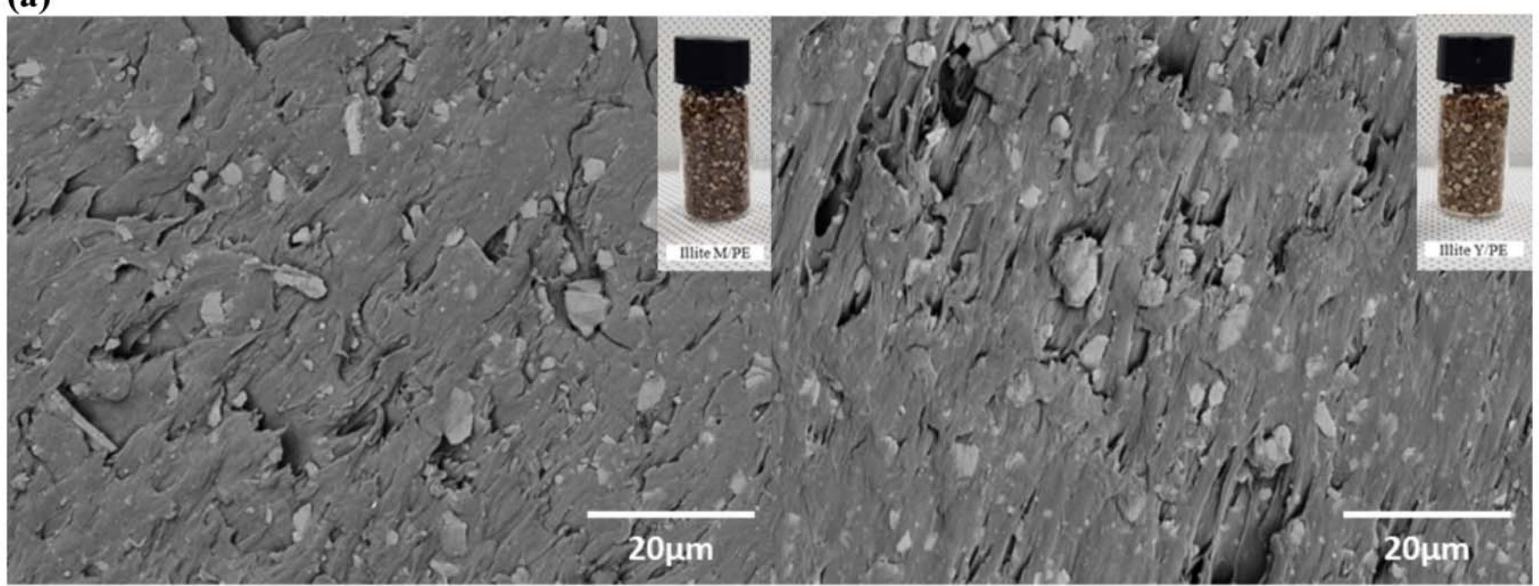

(b)

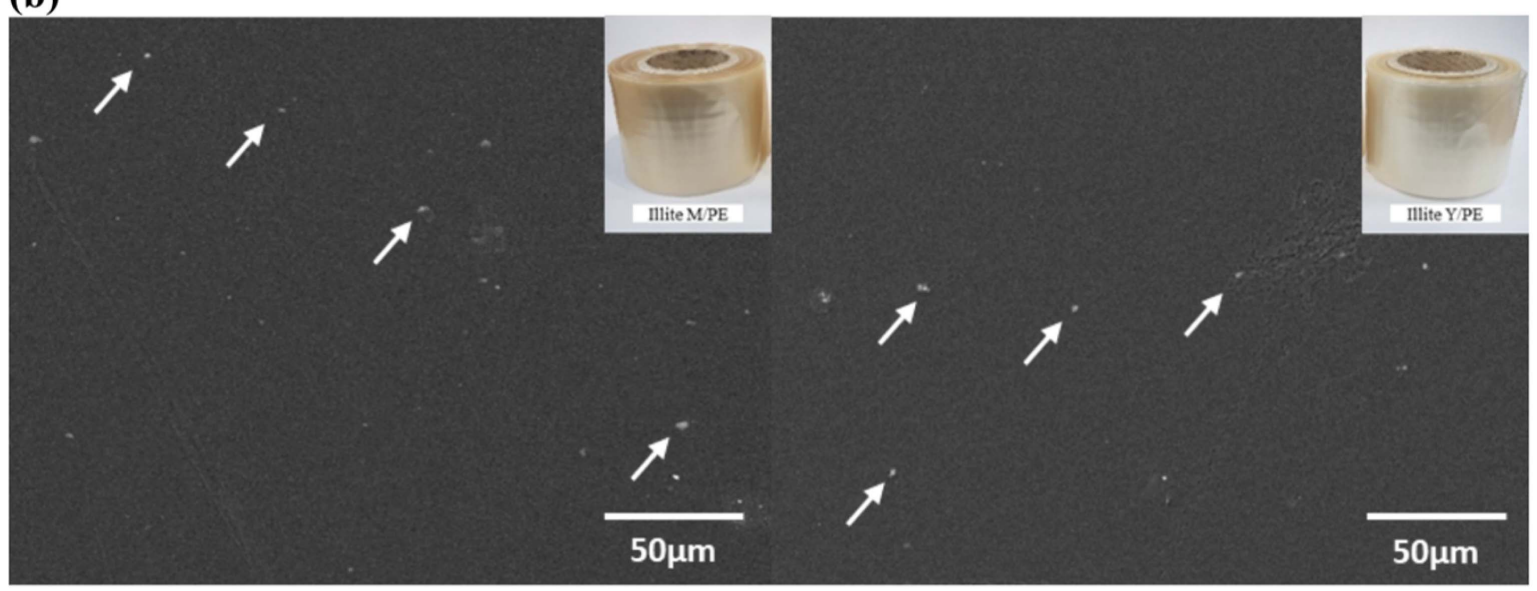

Fig. 3. SEM images of (a) illite-containing polyethylene masterbatch and (b) illite-containing polyethylene films. 


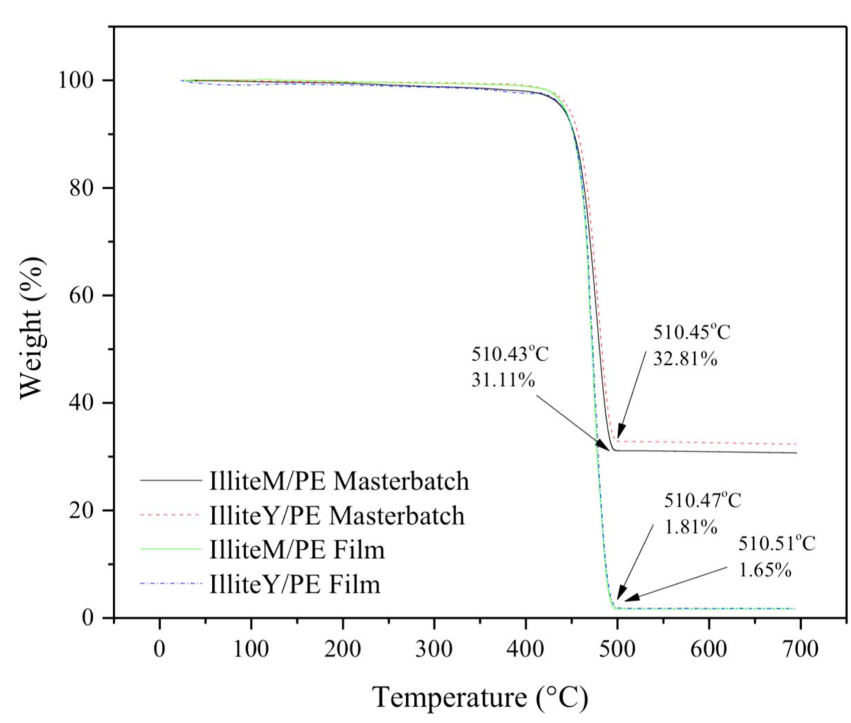

Fig. 4. TGA results of illite-containing polyethylene masterbatch and films.
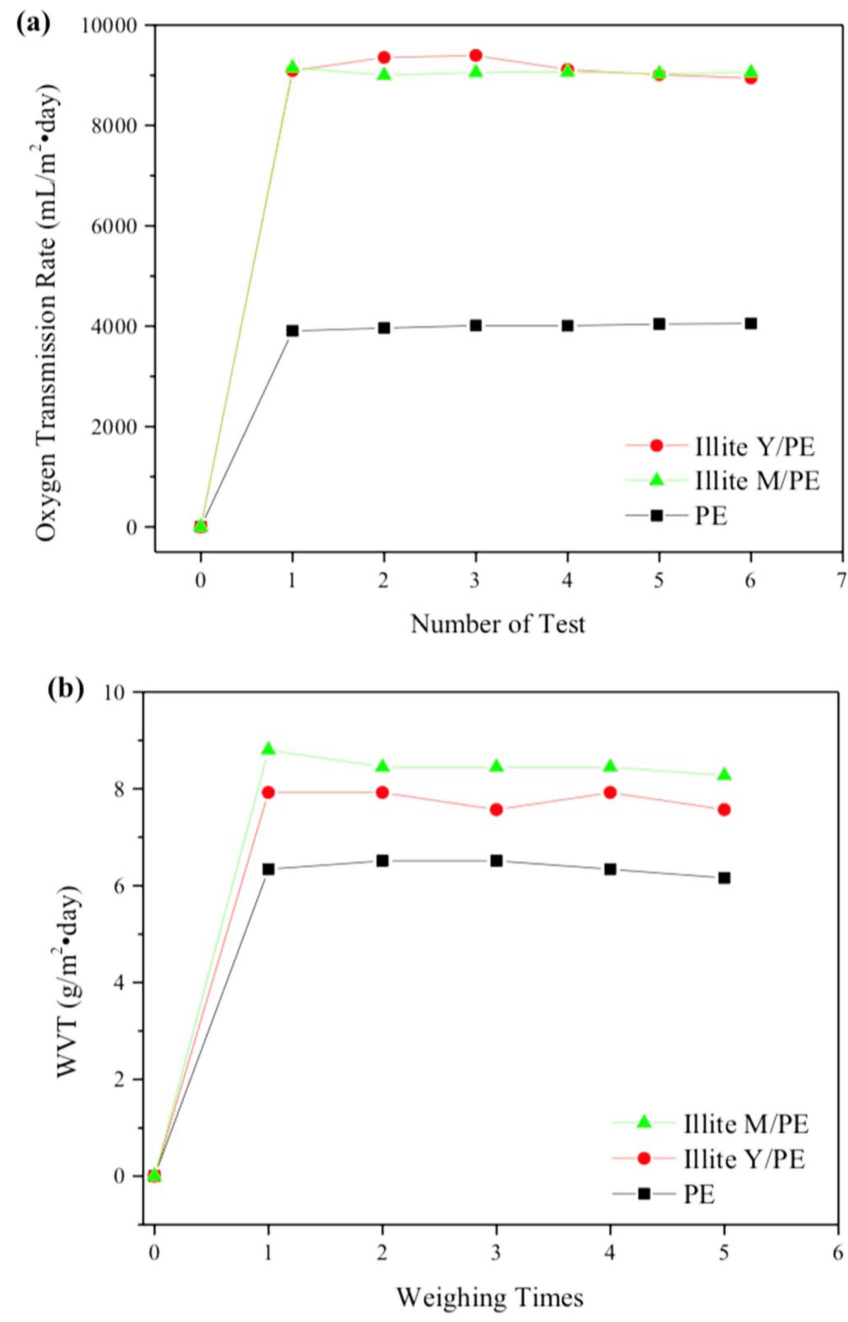

Fig. 5. (a) Oxygen transmission rate and (b) water vapor transmission rate of illite-containing polyethylene films. ability of the illite-containing polyethylene composite films, which was 9,057 in the Illite $\mathrm{M}$ film $\mathrm{mL} / \mathrm{m}^{2}$ and 9,148 in the Illite Y film $\mathrm{mL} / \mathrm{m}^{2}$. The oxygen permeability of the illitecontaining films was double the value of untreated polyethylene films $\left(3,995 \mathrm{~mL} / \mathrm{m}^{2}\right)$. In previous studies, platy nanoparticles with a high aspect ratio were used create a complicated gas permeation path, which reduced gas permeability. But in the present study, micro-sized particles with a low aspect ratio were used. The nanosized platy particles were layered, securing oxygen permeation paths through the interfaces between the illite particles and the polymer chains..$^{20,21)}$

Figure 5(b) shows the variation in moisture permeability of the illite-containing polyethylene composite films. The moisture permeability was determined by calculating the average of five measurements. The results showed that the moisture permeability of the general LDPE film, the Illite $\mathrm{M}$ film and the Illite Y film was 6.3715, 8.559 and $7.776 \mathrm{~g} /$ $\mathrm{m}^{2}$.day, respectively, indicating that the illite addition increased the moisture permeability. As in the case of oxygen permeability, the addition of illite particles between the polyethylene matrices might have secured spaces at the interfaces, affecting moisture permeation.

\section{Conclusions}

In the present study, illite was mixed with polyethylene in an attempt to increase the oxygen permeability and moisture permeability of polyethylene films. Illite-containing polyethylene films were prepared using a prepared master batch. SEM images showed that there was no agglomeration of the illite particles. The illite content in the illite-containing films prepared with the master batch ranged from $1.6 \%$ to $1.8 \%$, as determined by TGA. The oxygen permeability of the illite-containing polyethylene composite films was $9,057 \mathrm{~mL} / \mathrm{m}^{2}$ in the Illite $\mathrm{M}$ film and $9,148 \mathrm{~mL} / \mathrm{m}^{2}$ in the Illite Y film, which were about 2.3 times as high as that of the general polyethylene films $\left(3,995 \mathrm{~mL} / \mathrm{m}^{2}\right)$. The moisture permeability of the general polyethylene films, the Illite M film and the Illite Y film was 6.3715, 8.559 and $7.776 \mathrm{~g} /$ $\mathrm{m}^{2}$.day, respectively, indicating that the addition of illite increased moisture permeability.

The results confirmed that the illite-containing polyethylene composite films, with their higher oxygen permeability and moisture permeability, can be used as packaging materials to lower the concentration of oxygen generated by the respiration of fruit and agricultural and fishery products, or to enhance the discharge of ethylene gas generated in the ripening process, to maintain the freshness of agricultural, livestock and fishery products and improve storage quality.

\section{Acknowledgments}

This work was supported by a grant from the R\&D program funded by the Ministry of Trade, Industry and Energy 
(MOTIE), and Korea Institute of Ceramic Engineering and Technology (KICET), Republic of Korea.

\section{REFERENCES}

1. C. E. Tas, S. Hendessi, M. Baysal, S. Unal, F. C. Cebeci, Y. Z. Menceloglu, and H. Unal, "Halloysite Nanotubes/ Polyethylene Nanocomposites for Active Food Packaging Materials with Ethylene Scavenging and Gas Barrier Properties," Food Bioprocess Technol, 10 [4] 789-98 (2017).

2. M. A. Busolo and J. M. Lagaron, "Antioxidant Polyethylene Films Based on a Resveratrol Containing Clay of Interest in Food Packaging Applications," Food Packag. Shelf Life, 6 30-41 (2015).

3. N. H. Nasab, M. M. Jalili, and S. Farrokhpay, "Application of Paraffin and Silver Coated Titania Nanoparticles in Polyethylene Nanocomposite Food Packaging Films," J. Appl. Polym. Sci., 135 [8] 45913 (2017).

4. L. A. Naamani, J. Dutta, and S. Dobretsov, "Nanocomposite Zinc Oxide-Chitosan Coatings on Polyethylene Films for Extending Storage Life of Okra (Abelmoschus esculentus)," J. Nanomater., 8 [7] 479 (2018).

5. W. T. Arreola, H. S. Valdez, E. Peralta, J. L. Caa RdenasLoa Pez, and J. M. Eaquerra-Brauer, "Effect of a LowDensity Polyethylene Film Containing Butylated Hydroxytoluene on Lipid Oxidation and Protein Quality of Sierra Fish (Scomberomorus sierra) Muscle during Frozen Storage," J. Agric. Food Chem., 55 [15] 6140-46 (2007).

6. J. Kim, H. K. Jung, J. H. Kim, Y. H. Lee, S. H. Park, D. S. Choi, Y. H. Kim, S. J. Lee, C. W. Park, and B. K. Cho, "Effect of Pallet Size MAP using PA Film and LLPE Film on the Shelf Life of Tomatoes and Paprikas," J. Food Eng. Prog, 22 [2] 100-9 (2018).

7. H. S. Chung, P. Touvonen, and K. D. Moon, "Effect of Modified Atmosphere Packaging in Microperforated Film on Maintenance of the Quality of Fresh-Cut Apples," Korean J. Food Preserv., 15 [3] 347-51 (2008).

8. K. S. Lee, G. H. Kim, B. J. Seong, S. I. Kim, S. H. Han, S. S. Lee, M. Lee, and C. H. Yoo, "Components and Volatile Compounds According to Illite Addition in Saururus Chinensis Baill Cultivation," Korean J. Med. Crop Sci., 22 [3] 188-95 (2014).

9. J. W. Choi, C. S. Jhune, Y. P. Hong, M. A. Cho, and J. K. Kim, "Effect of 1-Methylcyclo Propene and Microperforated Film Packaging on Postharvest Quality of King Oyster Mushroom (Pleurotus Eryngii)," J. Mushroom, 10 [4] 191-97 (2012).
10. J. M. Seong, Y. G. Lee, J. W. Lee, and B. C. Cho, "Microporous High Density Polyethylene Film and Preparing Method Thereof," KR Patent, 100976121B1, 2009.

11. A. F. Gualtieri, S. Ferrari, M. Leoni, G. Grathoff, R. Hugo, M. Shatnawi, G. Paglia, and S. Billinge, "Structural Characterization of the Clay Mineral Illite-1M," J. Appl. Cryst., 41 402-15 (2008).

12. X. Liang, L. F. Hakim, G. D. Zhan, J. A. McCormick, S. M. George, and A. W. Weimer, "Novel Processing to Produce Polymer/Ceramic Nanocomposites by Atomic Layer Deposition," J. Am. Ceram. Soc, 90 [1] 57-63 (2007).

13. S. H. Jang, Y. S. You, and S. I. Park, "Developments of Degradable LDPE Films and Their Properties," J. Korean Soc. Environ. Technol, 12 [3] 182-88 (2011).

14. Y. C. Li and G. H. Chen, "HDPE/Expanded Graphite Nanocomposites Prepared via Masterbatch Process," Polym. Eng. Sci, 47 [6] 882-88 (2007).

15. P. Pokharel and D. S. Lee, "High Performance Polyurethane Nanocomposite Films Prepared from a Masterbatch of Graphene Oxide in Polyether Polyol," Chem. Eng. J., 253 356-65 (2014)

16. M. P. Villanueva, L. Cabedo, E. Gimenez, J. M. Lagaron, P. D. Coates, and A. L. Kelly, "Study of the Dispersion of Nanoclays in a LDPE Matrix Using Microscopy and InProcess Ultrasonic Monitoring," Polym. Test, 28 [3] 27787 (2009).

17. K. Prashantha, J. Soulestin, M. F. Lacrampe, M. Claes, G. Dupin, and P. Krawczak, "Multi-Walled Carbon Nanotube Filled Polypropylene Nanocomposites Based on Masterbatch Route: Improvement of Dispersion and Mechanical Properties through PP-g-MA Addition," eXPRESS Polym. Lett., 2 [10] 735-45 (2008).

18. X. Xia, S. Cai, and C. Xie, "Preparation, Structure and Thermal Stability of Cu/LDPE Nanocomposites," J. Mater. Chem. Phys., 95 [1] 122-29 (2006).

19. T. H. McHugh and J. M. Krochta, "Sorbitol- vs GlycerolPlasticized Whey Protein Edible Films: Integrated Oxygen Permeability and Tensile Property Evaluation," $J$. Agric. Food Chem., 39 [5] 1522-33 (2018).

20. M. Alexandre and P. Dubois, "Polymer-Layered Silicate Nanocomposites: Preparation, Properties and Uses of a New Class of Materials," Mater. Sci. Eng., 28 [1-2] 1-63 (2000).

21. J. W. Rhim, S. I. Hong, and C. S. Ha, "Tensile, Water Vapor Barrier and Antimicrobial Properties of Pla/Nanoclay Composite Films," LWT Food Sci. Technol., 42612 27 (2009). 